\title{
La teoría de Spinoza sobre la autoridad
}

\section{The Spinoza's Authority Theory}

\author{
María Luisa de la Cámara ${ }^{1}$ \\ Universidad de Castilla-La Mancha (España)
}

Recibido: 12-09-17

Aprobado: 08-10-17

\section{Resumen}

La noción de autoridad porta una pesada carga teológico-política. Spinoza examina críticamente los usos de esta noción para ponerla al servicio de su proyecto filosófico. En el presente trabajo se explicita la conexión de la autoridad con las líneas maestras de dicho proyecto, y se hace visible el tratamiento heterogéneo dado por Spinoza a la autoridad en el Tratado teológico-político, en la Ética y en el Tratado político en función de la diversidad de propósitos en cada uno de estos escritos.

Palabras-clave: autoridad, poder, iglesias, estado, tolerancia, teoría crítica.

\begin{abstract}
The notion of authority carries a heavy theological-political burden. Spinoza critically examines different uses of this notion, to put it at the service of his philosophical project. In the present work are explicit connection authority with the guidelines of the said project, and becomes visible the

\footnotetext{
${ }^{1}$ (marialuisa.camara@uclm.es) Maria Luisa de la Cámara es Licenciada en Filosofía y en Psicología. Es Doctora en Filosofía por la UCM. En la actualidad es Profesora de Filosofía en la Facultad de Letras de la Universidad de Castilla-La Mancha (Campus de Ciudad Real). Y Secretaria del Seminario Spinoza. Es co-directora de El gobierno de los afectos en Baruch Spinoza (2007); Spinoza: De la fisica a la historia (2008) y Spinoza y la Antropología en la Modernidad (2017). Y coordinadora del Boletín de Bibliografía Spinozista (Anales del Seminario de Historia de la Filosofia). Algunos trabajos en relación con la temática tratada son: "Spinoza y la sociedad civil", Spinoza contemporáneo (2009); "Fronteras de la tolerancia: la arquitectura del Tratado teológicopolítico y su fuerza perturbadora", Laguna. Revista de Filosofia, 31 (2012); "El común sentir de los hombres: ¿obstáculo o motor de la felicidad humana?”, Spinoza. La potenza del comune (2012); "Les femmes et la norme de la raison chez Spinoza", Normes et transgressions dans l'Europe de la première modernité (2013); "El conocimiento de los procesos mentales en la diana de la educación moral", Diálogos de la Universidad de Puerto Rico 100, (2016), "Descartes: ¿abstencionista o pensador político?”, Ingenium, 11 (2017).
} 
heterogeneous treatment given by Spinoza to the authority in the Theologicopolitical Treatise, in the Ethics and in the Political Treatise depending on the diversity of purposes in each of these writings.

Key-words: Authority, Power, Churches, State, Tolerance, Critical Theory.

Las investigaciones sobre Spinoza llevadas a cabo en las últimas décadas nos han acostumbrado a un catálogo extraordinariamente fecundo de nociones clave en su filosofía política. La mayor parte de esas nociones procedían de la herencia recibida, si bien sufrieron algún tipo de desplazamiento metafórico y los conceptos fueron re-significados para hacerles desempeñar un importante papel en la teoría. Nociones como lex y ius, potentia y potestas, imperium, multitudo, conatus, societas, entre otras, han sido objeto de numerosos e importantes estudios. En esa lista la noción de auctoritas (autoridad) ha recibido menos atención.

Y sin embargo la historia de la idea de autoridad, imprescindible en la filosofía clásica, porta una pesada carga teológico-política. Spinoza la examina críticamente y deja al descubierto su genealogía y el mecanismo psicológico de su reproducción, sus usos y manipulaciones, antes de utilizarla en su proyecto y de establecer sus límites. El presente trabajo no pretende realizar un análisis exhaustivo de la autoridad en Spinoza: nuestro propósito es, más bien, hacer explícita su conexión con las líneas maestras que sostienen su proyecto filosófico, particularmente con las nociones de potencia (potentia) y de poder (potestas). Y, a partir del tratamiento heterogéneo dado a esta noción en la Ética, en el Tratado teológico-político y el en Tratado político, poner las bases para una eventual reconstrucción de la teoría crítica de Spinoza acerca de la autoridad.

\section{Autoridad y poder en la tradición dominante}

Autoridad y poder son dos tópicos de la filosofía política cuyas primeras elaboraciones teóricas se pueden rastrear en la filosofía clásica, su praxis en la historia del pueblo hebreo ${ }^{2}$, su evolución y avatares en occidente a través del derecho romano y de la historia de la Iglesia.

En el libro I de la Política ${ }^{3}$ Aristóteles defendía que, si bien los asuntos de la casa interesan también a la acción política, el poder no se ejerce del mismo

\footnotetext{
${ }^{2}$ Moreau, P-F.: “Spinoza et 1'autorité d'un modèle: 1'État des Hebreux”, Spinoza. État et religion, Lyon, ENS Éditions, 2005, p. 21.

3 Aristóteles: Politica. Traducción, introducción y notas de Manuela García Valdés. Madrid, Gredos, 1988, p. 58 y ss.
} 
modo en las relaciones domésticas que en las relaciones cívicas. En efecto, en el ámbito doméstico, tanto si trata de relaciones heriles, como conyugales o paterno-filiales, todas las interacciones están basadas en el principio de autoridad y en la jerarquía; la politeia, en cambio, presupone la libertad e igualdad de todos ${ }^{4}$. La relación de autoridad es, para Aristóteles, algo natural que nace del reconocimiento de un individuo (esposa, hijo, esclavo) -o grupohacia un hombre admirado por su sabiduría o por alguna otra cualidad notable. A partir de ahí ese individuo -o grupo- renuncia a su criterio y a su autonomía para pasar a obedecer los dictados y recomendaciones del hombre admirado. La relación de autoridad era para el filósofo griego paradigma de toda otra relación jerárquica y dependiente entre un individuo autónomo o sui iuris que manda y otro que, aceptando su dependencia de aquél (alterius iuris), le obedece ${ }^{5}$. Este tipo de relación se da en el animal respecto al hombre (aunque el animal no tiene sentimientos), el hijo respecto al padre (relación de tipo monárquico), la mujer respecto al varón (relación de tipo aristocrático: la mujer puede deliberar, pero carece de autoridad), y el esclavo respecto al amo (que "participa de la razón tanto como para percibirla, pero no para poseerla"'). De todos estos personajes de la comedia humana, los siervos son destinados por la naturaleza a la esclavitud, y nada hay mejor para ellos que obedecer, perteneciendo a otro por el hecho de que no participan de la razón sino por un sentimiento vago.

Las relaciones de autoridad son pues diferentes del poder político tal como es descrito en el Libro III de la Política. En efecto, como acabamos de señalar, aquella instituye una jerarquía entre dos partes asimétricas en función del criterio de quien manda, mientras que en el plano del poder político todos los ciudadanos mandan y obedecen. Por añadidura, el poder político circula y es transferible, mientras que la autoridad es inalienable formando parte del patrimonio personal de quien ha sido investido de autoridad. Este último rasgo se traducirá en el mundo romano en el carácter vitalicio de los senadores (considerados autoridad) frente a la temporalidad de las magistraturas (cargos políticos).

En la cultura romana la noción de autoridad se tecnifica jurídicamente y busca establecer una relación equilibrada con el poder político. En efecto, ya desde el período republicano el derecho romano ${ }^{7}$ producía la normatividad jurídica siguiendo una estructura dual: el ámbito del poder (potestas) y el de la autoridad (auctoritas). Esta última tenía que ver con las aportaciones

${ }^{4}$ Op. cit., p. 78 y ss. Ese modelo de autoridad vale para explicar el dominio de la parte racional del hombre que manda sobre la parte irracional, que obedece, p. 81. San Agustín (Ciudad de Dios, XIX, 14) recoge la doctrina de Aristóteles sobre las relaciones domésticas; e igualmente la autoridad episcopal que es vigilancia y servicio y preocupación por los súbditos (Ciudad de Dios, XIX, 19).

${ }_{5}$ Política, Libro I, op. cit., pp. 57-59.

${ }^{6}$ Op. cit., p. 58.

${ }^{7}$ Paricio, J. y Fernández, A.: Historia del derecho romano y su recepción europea, Madrid, Centro de Estudios Ramón Areces, 1997, p. 34 y ss.

Araucaria. Revista Iberoamericana de Filosofía, Politica y Humanidades, año 20, n 39 . Primer semestre de 2018. Pp. 227-250. ISSN 1575-6823 e-ISSN 2340-2199 doi: 10.12795/araucaria.2018.i39.11 
jurisprudenciales basadas en el reconocimiento social del saber de algún jurista determinado, algunos de ellos famosos. En tanto que los pretores, por tratarse de una magistratura política, y como no eran juristas, tenían que ser asesorados por los jurisperitos -algunos de los cuales gozaron de reconocido prestigio y de autoridad ${ }^{8}$. Este hecho facilitó en la historia de la república la instauración de un período en el que convivieron con armonía la autonomía de criterio y la independencia de los juristas (autoridad) con los políticos (poder). Sin embargo, a partir de Augusto el supremo criterio en las deliberaciones no estará en el saber personal del jurista sino en la fuerza del emperador que lo refrenda con su imperium, siendo la autoridad jurídica subsumida paulatinamente por el poder del princeps.

No podemos dar cuenta aquí de los avatares experimentados por la noción de autoridad a lo largo de la Edad Media, por lo que hemos de contentarnos con subrayar el rasgo de obediencia voluntaria o aceptación implicado en ese tipo de interacciones. En efecto, en la fenomenología de las relaciones de autoridad, lo primero en aparecer desde un punto de vista psicológico es la admiración y el reconocimiento de la superioridad de alguien por un individuo, o un grupo, que se sujeta a sus opiniones y decisiones. La obediencia incondicional de ese individuo, o grupo de individuos, a otra persona engendra enseguida la "servidumbre" voluntaria a la autoridad - una de las fuentes tradicionales de la normatividad.

Siglos después Hobbes aprovechará la eficacia de ese mecanismo psicológico para revestir de legitimidad (autoridad) el poder absoluto del leviatán ${ }^{9}$. No es difícil percibir en el pacto de alienación del derecho individual la misma lógica de reconocimiento y obediencia, de jerarquía y dependencia, propia de las relaciones de autoridad domésticas descritas por Aristóteles en la Política. Pero Hobbes es jurista, por lo que da al acto por el que cada uno aliena su derecho natural a favor del soberano la forma jurídica y voluntaria de una autorización. De tal manera que la alienación del derecho natural de cada individuo en favor del poder soberano es consecuencia inexorable del reconocimiento previo de la autoridad de otro, y precisamente desde esa autorización previa por parte de cada individuo. He aquí la fórmula propuesta por Hobbes en el Leviatán como base legitimadora del pacto cívico: "Autorizo y concedo el derecho de gobernarme a mí mismo, dando a esa autoridad a este hombre o a esta asamblea, con la condición de que tú también le concedas tu derecho de igual manera, y les des autoridad en todas sus acciones".

\footnotetext{
${ }^{8}$ Op. cit., p. 91.

${ }^{9}$ El atributo que expresa el poder absoluto y supremo del estado se llama soberanía y se manifiesta en la capacidad para legislar. Bodino utilizó por primera vez este término indicando que la autoridad debe ser piramidal y jerarquizada (Seis libros sobre la república, 1576). Cfr. Vallespín, F.: "El poder político y los orígenes del estado" (p. 75 y ss.), Psicología de las relaciones de autoridad y de poder. Jiménez, F. (Coord.), Barcelona, UOC, 2006.
} 
Estamos ante un desplazamiento al plano político del modelo de autoridad característico, en el mundo griego, de las relaciones amo-esclavo, padres-hijos y conyugues. Con Hobbes la autorización, ahora artificial, tendrá sin embargo consecuencias penales y políticas, ya que se traduce en obligaciones coactas para los súbditos. En cualquier caso, el poder coactivo del estado se legitima por la previa autorización de cada individuo; lo que explica que la majestad del estado sea soberana, pues ha quedado revestida de los propios atributos de la autoridad: el reconocimiento, la inalienabilidad y su carácter absoluto e indivisible ${ }^{10}$. Toda la violencia del poder que en adelante pueda ejercer el soberano queda automáticamente legitimada por el acto de "autorización" precedente. El fundamento del pacto de estado como cesión voluntaria de autoridad. A partir de ese momento, es soberano (sui iuris) quien queda autorizado por cada ciudadano para ejercer criterio y regular las acciones de todos (de quien a partir de ese momento es alterius iuris). Los derechos del estado soberano enumerados en el Leviatán (1651) son muy amplios y van desde el poder de legislar y juzgar, decidir la guerra y la paz, cuestiones de administración pública y economía hasta el derecho de censura, de educación e instrucción, disposiciones morales y confesión religiosa del ciudadano. Los súbditos quedan protegidos por ese estado monstruoso conservando su derecho a circular libremente.

Spinoza ha leído a Hobbes ${ }^{11}$ y sabe que, para él, cada individuo ha cedido al poder soberano (estado) su derecho natural a gobernarse (concedida por autoridad divina) merced a una autorización. Pero Spinoza de ninguna manera está de acuerdo con Hobbes. ¿Puede concebirse mayor absurdo que la alienación voluntaria del derecho de naturaleza, signar una autorización para que otro pueda servirse absolutamente de esa potencia? La tesis hobbesiana no sólo carece de lógica, sino también de fundamento y de utilidad. Pues, si el acto de "autorización" hobbesiano es de naturaleza jurídica, resulta impensable en el estado de naturaleza donde no existe aún ninguna obligación ni ley civil. Por el contrario, Spinoza conserva siempre íntegra la autoridad de cada uno. Así lo expresa en una conocida carta dirigida a Jarig Jelles:

Por lo que respecta a la política, la diferencia entre Hobbes y yo consiste en que yo conservo siempre incólume el derecho natural y en que yo defiendo que, en cualquier Estado, al magistrado supremo no le compete más derecho sobre los súbditos que el que corresponde a la potestad con que él supera al súbdito, lo cual sucede siempre en el estado natural ${ }^{12}$.

\footnotetext{
${ }^{10}$ Para Aristóteles la autoridad era cualidad inalienable, intransferible e integra el patrimonio de la persona a la que se le ha reconocido.

${ }^{11}$ En el catálogo de su biblioteca figura un ejemplar In $12^{\circ}$ del De cive, Amsterdan, Elzevir, 1647

12 Carta 50, Spinoza. Correspondencia. Traducción, introd. y notas, Domínguez, A., Madrid, Alianza, 1988, p. 308 [G IV, 239].
} 
La dificultad que suscita la tesis del pacto hobbesiano, la falta de lógica de esa autorización para reconocer la autoridad suprema al Leviatán, explican que al inicio del capítulo XVII del Tratado teológico-político Spinoza considere el mecanismo del pacto como una "elucubración teórica" o una ficción alejada de la realidad: "Nadie, en efecto, podrá jamás transferir a otro su poder ni por tanto, su derecho, hasta el punto de dejar de ser hombre; ni existirá jamás una potestad suprema que pueda hacerlo todo como quiera"13. En consecuencia, si un estado teme al pueblo es porque éste conserva algún poder $\mathrm{y}$, si lo conserva, es que no lo cedió íntegramente.

Por añadidura, Spinoza tampoco acepta el desplazamiento a la esfera política del modelo aristotélico de autoridad bajo el paradigma de la servidumbre doméstica. Autoridad y poder político son para nuestro filósofo dominios teóricos inconmensurables: "Admitimos una gran diferencia entre el esclavo, el hijo, el súbdito" - escribe Spinoza dialogando con Aristóteles-, "(...) súbdito, finalmente, es aquel que hace, por mandato de la autoridad suprema, lo que es útil a la comunidad $\mathrm{y}$, por tanto, también a él"14.

\section{Uso crítico de la noción de autoridad en el Tratado teológico-político}

Ahora bien, aunque autoridad y poder político $^{15}$ definen en teoría dos clases de relaciones interhumanas diferentes y sean inconmensurables, de facto se han dado a lo largo de la historia numerosos fenómenos de solapamiento, quedando absorbida la autoridad por el poder o el poder por la autoridad. Alexandre Matheron explica con detalle cómo los pontífices cristianos, una vez hubieron garantizado su independencia y autonomía respecto al poder civil, fueron imponiendo progresivamente su supremacía sobre las comunidades cristianas: "une fois consolidé leur pouvoir «spirituel», les Papes s'en servirent pour mettre le pouvoir temporel sous leur coupe"16. Y rubrica unas líneas más

13 Tratado teológico-político, Traducción, introducción y notas A. Domínguez, Madrid, Alianza, 1986, p. 350 [G III, 201].

${ }^{14}$ TTP XVI, op. cit., p. 341 [G III, 195]. Esclavo es quien obedece para la utilidad del señor; hijo es quien obedece a los padres por la utilidad; pero súbdito es quien obedece a la autoridad suprema para la común utilidad.

15 El poder implica potencia y fuerza material, poder visible y afirmado por medios externos, la autoridad se ejerce de forma invisible y va asociada al conocimiento y a la enseñanza, a la tradición. René Guénon, Autoridad espiritual y poder temporal, Barcelona, Paidós, 2001, p. 29ss. El esotérico autor lleva a cabo un análisis metafísico de las relaciones de autoridad y poder, sobre la base del esquema general conocimiento-acción. La modernidad occidental habría optado por otorgar supremacía a la acción, al poder. Por otra parte, el lector podrá encontrar una recopilación ordenada de definiciones del poder, en: F. Jiménez, "Perspectivas teóricas y definicionales sobre poder y autoridad", F. Jiménez (Coord), Psicología de las relaciones de autoridad y poder, Barcelona, UOC, 2006, pp. 15-39.

${ }^{16}$ Matheron, A.: Le Christ et le salut des ignorants, Paris, Aubier, 1971, p. 272. Recomendamos encarecidamente la lectura de los artículos de contenido político recogidos en el volumen: Matheron, 
abajo: "Une «ingens libido sacra officia administrandi» se répandit dans toute 1'Église: la piété fit place à l'ambition et à une sordide avidité".

El Tratado teológico-político contiene una amplia reflexión sobre la relación entre la autoridad eclesial y el poder político, mostrando la génesis de la conflictividad entre esas dos fuentes de normatividad cuando sus competencias respectivas no están adecuadamente delimitadas, y proponiendo una solución al choque de intereses entre las iglesias y el estado. El análisis de Spinoza incluye referencias al estado hebreo y a la historia de Roma; pero el propósito del libro no es historiográfico, sino que ofrece una deliberación -basada en la razón y en la experiencia ${ }^{17}$ - acerca de un problema político de plena vigencia en su tiempo. Pues el principal obstáculo para mantener la estabilidad de un estado es precisamente la división interna de la población nacida de las pasiones humanas del vulgo, agitadas y manipuladas por estas dos fuentes de normatividad: la autoridad de las iglesias y el poder político. Mas esa conflictividad latente entre la ley civil y las normas religiosas remite a su vez a otra cuestión previa: el debate entre la fe y la razón.

Spinoza, en un primer momento, zanja la cuestión del primado entre la autoridad de las Escrituras ${ }^{18}$ y la razón, defendiendo su inconmensurabilidad. Inmediatamente después el filósofo hace una defensa radical de la libertad de expresión en el estado, limitando las pretensiones hegemónicas de las autoridades religiosas tanto como la dejadez y/o el exceso de celo del poder político. Dado que este debate tiene un contenido teológico-político, el recurso a la historia sagrada y al pueblo hebreo queda justificado por la visibilidad que aporta a sus ideas (experiencia y razón) ${ }^{19}$.

A propósito de la primera parte de este doble debate sobre autoridad y poder, no está de más insistir en que Spinoza refrenda la autoridad que se debe conceder a las Sagradas Escrituras (capítulo XV del Tratado teológicopolítico). Aunque de ningún modo esa autoridad religiosa -que lo es en materia de recomendaciones prácticas a la justicia y caridad- tiene que ser defendida por medio de argumentos racionales ni de forma matemática ${ }^{20}$. Razón y fe son modalidades epistémicas inconmensurables, aunque apunten a

A.: Études sur Spinoza et les philosophies de l'âge classique, Lyon, ENS, 2011; y de manera particular, "Spinoza et le pouvoir", pp.67-79.

17 Dualidad epistémica subrayada por Moreau, P-F. en Spinoza. L'expérience et l'éternité, Paris, PUF, 1994. Por lo demás, cfr. Aristóteles, Política I, ed. cit, p. 56: "No es difícil examinarlo teóricamente con la razón y llegar a comprenderlo a partir de la experiencia".

${ }^{18}$ Diversas cuestiones específicas sobre la autoridad de la Escritura son examinadas en: VVAA, Groupe de recherches Spinozistes $n^{\circ} 4$, L'Écriture Sainte au temps de Spinoza et dans le système spinoziste. Paris, Presses Universitaires de Paris-Sorbonne, 1992.

${ }^{19}$ Cfr. P-F. Moreau, "Spinoza et l'autorité d'un modèle: l'État des Hebreux", Spinoza. État et religion, ENS, Lyon, 2005, pp. 21-33. Todos los artículos del volumen son muy esclarecedores en relación con el tema que se trata aquí.

${ }^{20}$ TTP, XV, p. 326 [G III, 185]. 
una misma finalidad práxica. Se trata de dos esferas independientes ${ }^{21}$, pero no contradictorias, por lo que querer juzgar la Escritura con criterios racionales (es decir, en términos de verdades) daría al traste con su adecuada interpretación ${ }^{22}$ fomentando el intento hegemónico de la una sobre la otra. De manera que, en tal caso, o bien la razón quedaría supeditada a la fe, tal como defendiera en el siglo XIII el toledano R. Jehudá Alfakar; o la fe quedaría bajo la tutela de la razón como en Maimónides ${ }^{23}$. Spinoza se distancia de uno y otro, y defiende un proyecto personalísimo de hermenéutica bíblica inmanente a la Escritura -apoyándose curiosamente en Moisés. En efecto, su figura y sus acciones reforzadas por los signos hicieron de él una autoridad para el pueblo hebreo que basará su obediencia en la creencia en la ley mosaica (de supuesto origen divino) que ordena la práctica de la piedad y la caridad.

Por lo demás, Spinoza defiende la autoridad suprema de la razón en materia especulativa: "En cambio, acerca de la verdad de los objetos puramente especulativos, ningún espíritu da testimonio, excepto la razón, puesto que, como hemos probado, sólo ella reclamó para sí el dominio de la verdad"24. En efecto, al final del capítulo VII, ya se había negado validez universal al modelo de constitución mosaica y al desplazamiento de ese paradigma al occidente actual, rechazando con ello la supuesta autoridad del Romano Pontífice ${ }^{25}$. Por el contrario, para Spinoza "cada uno tiene el derecho de pensar libremente" incluso en materia religiosa, de tal manera que la autoridad suprema para explicar la religión y emitir un juicio sobre ella residirá en cada uno, en la luz natural de la razón -común a todos los hombres- y no en alguna supuesta facultad sobrenatural. Definitivamente la teocracia hebrea no es un paradigma universal:

El único motivo, en efecto, de que la autoridad suprema para interpretar las leyes y el juicio definitivo sobre los asuntos públicos residan en un magistrado, consiste en que son de derecho público; y por eso mismo la autoridad suprema

${ }^{21}$ TTP, XV, p. 329 [G III, 188] critica la confusión de esas dos facultades, y la necesidad de separar la filosofía de la teología.

22 A la cuestión: ¿quién debe ser el intérprete de la Escritura?, Spinoza responde que la lectura debe hacerse desde la propia Escritura pero no por la Escritura. Se opone a quienes hacen prevalecer la fe sobre la razón (Alfakar) y a ésta sobre la fe (como Maimónides y Meyer). Propone una serie de reglas para su interpretación en TTP, VII.

23 Spinoza reenvía al lector al capítulo VII de esta misma obra, acerca de la interpretación de la Escritura, donde había refutado las tesis de Maimónides. Spinoza coteja sus argumentos con los adversarios discrepantes desde [112], p. 212. Sus divergencias con Maimónides quedan recogidas en $[113,114,115,116$ y 117]. Sumariamente: "Nosotros rechazamos, pues, la opinión de Maimónides por perjudicial, inútil y absurda" - confiesa Spinoza (p. 217). En efecto, si los filósofos fuesen autoridad para evaluar la Escritura, automáticamente se convertirían en una "nueva autoridad eclesiástica", un nuevo tipo de sacerdotes y pontífices, ridiculizados por el pueblo (p. 215) [G III, 114].

${ }^{24}$ TTP, XV, p. 329 [G III, 188]. He abordado con anterioridad el tema de la autoridad de la razón en la correspondencia de Spinoza con Albert Burgh en, "Defensa de la razón por Spinoza", M. Luisa Ribeiro-Ferreira et al. (eds.), Spinoza. Ser e agir. Lisboa, CFUL, 2011, pp. 161-174.

25 TTP VII, 217ss [G III, 117]. 
para explicar la religión y emitir un juicio sobre ella, residirá en cada uno, justamente porque es de incumbencia de cada cual (ibídem).

Spinoza zanja la cuestión del primado de fe y razón en materia de autoridad defendiendo a las dos -cada una en su ámbito específico- y proclamando al mismo tiempo la independencia de teología y filosofía ("cada una defiende su dominio sin oposición de la parte contraria") ${ }^{26}$. Su confusión, sea involuntaria o intencionada, es fuente de conflictividad social y política: “...he mostrado, siempre que se presentó la ocasión, los absurdos, inconvenientes y perjuicios que se han derivado de que los hombres hayan confundido de las formas más extrañas estas dos facultades y no hayan atinado a distinguirlas con precisión ni a separar la una de la otra", rubrica el filósofo.

Alguien podría objetar que en tiempos de Moisés no existió conflicto alguno entre la ley civil y las normas sagradas. Y así sucedió ciertamente, pero sólo durante ese período, debido a que "las leyes de Moisés constituían el derecho público de la patria y por eso necesitaban para su conservación cierta autoridad pública"27. Pero de ello no se sigue que aquel modelo de teocracia tenga validez universal.

En efecto, la historia del pueblo hebreo no ha sido homogénea, pudiéndose diferenciar varias etapas políticas. Así, durante el mandato de los jueces, los poderes temporales no estaban subordinados a los sacerdotes y profetas. Había un equilibrio logrado desde la independencia en sus respectivas tareas: los sacerdotes tenían criterio, los gobernantes aplicaban la ley. Desgraciadamente esa situación no permaneció y, a partir del período de los reyes, se multiplicaron los conflictos internos y externos. La división del pueblo hebreo tiene su origen en la ambición ilimitada de la casta sacerdotal que privilegió a una de las tribus (la tribu de los levitas) frente al resto, engendrando el malestar social y fomentando la fragmentación del pueblo.

Moreau ha enfatizado este aspecto subrayando que la teocracia no es el único régimen político del estado hebreo ni puede ser paradigma para la Europa del siglo XVII ${ }^{28}$. Es verdad que Moisés fue alguien que dio leyes a un pueblo que había estado sometido y así basó su legitimidad en el afecto que todos sentían hacia Dios. Es verdad que bajo su gobierno no hubo conflictos, porque su constitución implicaba el reconocimiento personal de la autoridad de Dios. Es cierto que había una fuente única de normatividad que implicaba la sacralización de los usos y costumbres. Y hasta de un alma común que latía

${ }^{26}$ TTP XV, p. 330 [G III, 188]. Sobre la religión natural en Spinoza, sugiero la pertinencia del trabajo de Francisco Javier Espinosa, "Religión, salvación y autonomía en Spinoza", en Blanco, J.: (coord.), Espinosa. Ética e política. Santiago de Compostela, Universidade de Santiago de Compostela, 1999, pp. 211-219; y también "La religión natural en Spinoza. Algunas consideraciones desde Kant, Schleiermacher, Bonhoeffer y Cox", Cuadernos Spinoza n 7, Ciudad Real, 1996.

${ }^{27}$ TTP VII, p. 217 [G III, 117].

${ }^{28}$ Moreau, P-F.: Spinoza. État et religion, op. cit., p. 28. 
al unísono bajo los mismos afectos religiosos de admiración, obediencia y esperanza. Pero esa constitución no tiene ya cabida en un siglo que despierta a la racionalidad científica ${ }^{29}$.

En fin, las consideraciones de los párrafos anteriores prueban fehacientemente la importancia del binomio autoridad-poder en el Tratado teológico-político; y reflejan los encuentros y desencuentros de las autoridades eclesiales con el poder civil en el estado moderno. El planteamiento de Spinoza como propuesta de solución de los conflictos no pasa por suprimir la autoridad, sino que se basa en esclarecer los usos del término en las diferentes esferas y en mostrar sus enredos antes de delimitar críticamente sus fronteras con el poder político. Autoridad se le reconoce a los profetas en materia de regulación de la conducta (Prefacio) ${ }^{30}$, a los apóstoles en materia de enseñanza (capítulo $\mathrm{XI})^{31}$, a Pablo y a las Escrituras en el plano moral (capítulo XV) ${ }^{32}$ : implica la imputación de una cualidad que les capacita para tener criterio (opinión y consejo) en materia de conducta, pudiendo juzgar las conductas contrarias a la piedad y a la obediencia religiosa ${ }^{33}$. En este sentido, la autoridad eclesial es una fuente de normatividad diferente del poder político, tal como sucediera con el Senado en la Roma clásica ${ }^{34}$.

Pero, junto con este primer uso del término autoridad, hay en el tratado de 1670 ocurrencias en las que se identifica la autoridad con el poder político supremo (imperium). La autoridad, fuente de legitimación del poder supremo, es entonces soberanía civil, poder único e intransferible ${ }^{35}$ (imperium) para instituir

\footnotetext{
${ }^{29}$ Antonio Hermosa, La Teoría del estado de Spinoza, Sevilla, Servicio de Publicaciones de la Universidad de Sevilla, 1989, p. 12-13.

30 "Una vez aclarado esto me fue fácil establecer que la autoridad de los profetas tan sólo tiene valor en lo que se refiere a la práctica de la vida y a la verdadera virtud; pero que en lo demás sus opiniones importan poco" (p. 68) [G III, Praef. 9; VII, 102; XI, 151, XV, 185, XVII, 220, XVIII, 223, XIX, 238].

31 “...como enseguida probaré a los apóstoles no sólo les fue concedida la virtud de profetizar, sino también la autoridad de enseñar" (p. 281). Y más adelante, p. 283.

32 "la autoridad de los sagrados libros depende de la autoridad de los profetas" (TTP, XV, p. 326)

33 En un sentido parecido, la Carta 56 hace referencia a aquellos filósofos cuya autoridad es admitida por Spinoza.

${ }^{34}$ Cfr. Arendt, Hanna: “¿Qué es autoridad?”, Entre el pasado y el futuro, Barcelona, Península, 1996. Su tesis es que a partir de la Modernidad se confunden tres nociones: autoridad, poder y violencia. En la cultura romana, la autoridad estaba asociada con la tradición: es decir, con la fundación y los orígenes (auctoritas-augere-aumentar). La autoridad de los vivos dependía de los primeros fundadores. El senado o los patres de la patria eran tenían la autoridad; el pueblo, el poder (SPQR). Por la autoridad se recibe una opinión, o un consejo, se ratifica una decisión y se aprueba o se rechaza: como los auspicios y los dioses que tienen autoridad sobre y entre los hombres. Según Plutarco la autoridad en la república romana funcionaba como un contrapeso que equilibraba las cosas. Esa autoridad se convertía en un ejemplo moral. Dice así Hanna Arendt: "En la medida en que esa tradición no se interrumpiera, la autoridad se mantenía inviolada y era inconcebible actuar sin autoridad y tradición, sin normas y modelos aceptados y consagrados por el tiempo, sin la ayuda de la sabiduría de los padres fundadores" (p. 197).

35 Entonces, si la autoridad de Moisés se identifica con su poder político, se comprende que las propiedades asociadas a aquella -unidad e inalienabilidad- se desplacen igualmente al poder político. Spinoza explica así que Moisés no transfirió su autoridad/poder a sus sucesores, ni a dominadores
} 
y derogar leyes, decidir la guerra y la paz, elegir representantes, nombrar jueces, elegir al sucesor, y administrar absolutamente todas las obligaciones de las sumas potestades ${ }^{36}$. Autoridad y poder político resultan entonces intercambiables. Así aparece, por ejemplo, en el capítulo $\mathrm{V}^{37}$ a propósito del pacto del pueblo hebreo con Dios; y en el capítulo XVII al hablar del pacto de los hebreos con Dios a través de la autoridad que el pueblo había transferido a Moisés. En ambos casos -es decir, en la teocracia-autoridad y poder coinciden. Spinoza acepta la figura de la promesa de obediencia a Dios (autoridad) para explicar la transferencia de derecho desde el pueblo al gobernante: "Esta promesa o transferencia de derecho a Dios se efectuó de la misma forma que nosotros hemos concebido para la sociedad en general, cuando los hombres deciden renunciar a su derecho natural" -comenta Spinoza hobbesianamente.

Sin embargo, en el caso del estado hebreo mencionado por Spinoza, la legitimación del poder por la autoridad divina -propia de la constitución teocrática- no implicó la cesión forzada del derecho en su integridad, ni la escisión de la población entre quien manda y obedece. La obediencia no es tanto externa cuanto interna: "Quien está sometido a otro, es quien decide con toda su alma obedecerle en todos sus preceptos; y quien tiene la máxima autoridad es quien reina sobre los corazones de los súbditos"38. La sumisión voluntaria del pueblo a Dios, primero, y a Moisés, después, garantiza una forma de gobierno popular dominado por un sentimiento de cohesión y de buen entendimiento con los administradores del estado. La armonía predominante se manifestó en una absorción normativa que hace de las enseñanzas religiosas leyes civiles. Spinoza lo expresa en los siguientes términos:

Es decir, los dogmas de la religión no eran enseñanzas sino derechos y mandatos, la piedad era tenida por justicia y la impiedad por crimen e injusticia. Quien faltaba a la religión, dejaba de ser ciudadano y era tenido ipso facto por enemigo; quien moría por la religión se consideraba que moría por la patria; y en general no se establecía diferencia alguna entre derecho civil y religión. Por eso pudo recibir el estado el nombre de teocracia, puesto que sus ciudadanos no estaban sujetos a otro derecho que al revelado por Dios" ${ }^{\text {39. }}$.

sino a administradores del estado (p. 362); sólo dividió su gestión o administración entre los levitas, los príncipes, el ejército y el pueblo. La misma idea aparece más adelante, por ejemplo en el capítulo XIX (p. 400). El pueblo hebreo se identificaba con las normas y los valores comunes tanto que "no les debía parecer esclavitud sino libertad y nadie deseaba lo prohibido sino lo preceptuado" (p. 373) [G III, XVII, 216]. A pesar de lo cual ese modelo se hundió debido a las luchas internas entre levitas y príncipes, el abuso de autoridad de unos y otros alimentó la rebelión del pueblo contra su autoridad.

${ }^{36}$ Todos están bajo la suma potestad, p. 352 [G III, XVII, 202].

37 "como la obediencia consiste en que alguien cumpla las órdenes por la sola autoridad del que manda...el pueblo sigue siendo libre porque no actúa a través de la autoridad de otro, sino por su propio consentimiento" (pp. 158-9) [G III, 74]. Tal era el caso de la teocracia a raíz del primer pacto de los hebreos con Dios.

${ }^{38}$ TTP, XVII, p. 352 [G III, XVII, 202].

${ }^{39}$ TTP, p. 375-358 [G III, XVII, 206]. 
Las monarquías cristianas se han legitimado empleando una lógica similar ${ }^{40}$ que simula el origen divino de la autoridad del monarca: "Otros, sin embargo, lograron más fácilmente hacer creer que la majestad regia es sagrada y hace las veces de Dios en la tierra, que tiene su origen en Dios y no en los votos y en los acuerdos de los hombres, y que se mantiene y conserva por una singular providencia y ayuda de Dios"41. Pero la aparente analogía estructural entre la constitución teocrática hebrea y la monarquía cristiana no puede ocultar sus diferencias: "La única diferencia hubiera consistido en que el régimen monárquico (...) se rige por un decreto de Dios oculto al monarca mientras que el estado de los hebreos se regía por un decreto de Dios sólo revelado al monarca".

Ahora bien, si en el capítulo XVII del Tratado teológico-político es presentado el estado hebreo como un modelo estable y socialmente democrático, es lógico preguntarse por las causas de su destrucción que llevó a la diáspora del pueblo. El capítulo XVIII analiza ese deterioro atribuyéndolo fundamentalmente al abuso hegemónico de los levitas. En efecto, a diferencia de lo sucedido durante el período mosaico cuando el poder político regulaba las cuestiones religiosas ("El derecho del pontificado siempre dependió de la decisión de la suprema potestad, y los pontífices nunca lo poseyeron sin que fuera unido al principado. El derecho sobre las cosas sagradas estuvo sin restricción alguna en poder de los reyes..."42), con los levitas $-\mathrm{y}$ más tarde también en los estados cristianos- ha sucedido justamente lo contrario ${ }^{43}$. En efecto, los eclesiásticos han querido hacer valer su autoridad, imponiendo sus dogmas y creencias a los reyes y con ello penetrando todas las estructuras del estado, lo que explica las numerosas disputas y guerras -como también sucediera con los reyes y los pontífices de los hebreos. De ahí la necesidad de establecer una demarcación y de fijar los límites ${ }^{44}$. Este será el propósito de los capítulos XIX y XX del Tratado teológico-político.

Así pues, la razón reforzada por la historia permite extraer ciertas lecciones para prevenir los conflictos entre autoridad y poder. Por lo que, en primer lugar, si se quiere evitar la tiranía o autoritarismo de las iglesias, y su injerencia en cuestiones cívicas, hay que defender la potestad del estado sobre el ius circa sacra -como forma de defender su imperium. Spinoza escribe:

${ }^{40}$ Semejanzas y diferencias son expuestas en TTP XVII, p. 360.

${ }^{41}$ TTP, XVII, p. 357 [G III, 206].

42 TTP, p. 401, 406 [ G III, XVIII, 234, 238].

43 TTP, p. 404-405 [G III, XVIII, 237].

${ }^{44}$ Cfr. Locke, J. en sus tratados sobre la tolerancia (Ensayo y Carta sobre la tolerancia, Madrid, Alianza, 2009) defenderá la independencia de iglesia y estado; Locke comienza estableciendo con todo detalle la separación de los ámbitos competenciales de las iglesias y del magistrado civil: sus fines, su modus operandi, su esfera de actuación; delimita sus obligaciones y deberes y analiza algunos conflictos. 


\begin{abstract}
Por consiguiente, las supremas potestades de nuestros días al no tener ningún profeta ni estar obligadas a aceptarlo (pues no están sujetas a las leyes de los hebreos), poseen, sin restricción alguna, este derecho, aunque no sean célibes; y siempre lo mantendrán, con la única condición de que no permitan que los dogmas religiosos alcancen un número elevado y que se confundan con las ciencias $^{45}$.
\end{abstract}

Y, cuando el objetivo es impedir el abuso de poder del estado sobre el derecho de expresión de los individuos que lo integran, resulta imperativo recortar el exceso de normatividad de la ley civil sobre los asuntos de conciencia -aumentando el nivel de tolerancia política hasta proclamar abiertamente la libertad de pensamiento y expresión (TTP, capítulo XX). Puesto que la libertad civil es el reconocimiento del poder inalienable e intransferible que la naturaleza ha dado a cada hombre haciéndolo el único dueño de su pensamiento. Cada individuo es la máxima autoridad. Por lo que absolutamente nada, ninguna ley divina ni humana, podrá legitimar ninguna clase de coacción que obligue a los hombres a pensar esto mejor que aquello, o a ser virtuosos, sabios o prudentes. Por eso sobra la autoridad del Sumo Pontífice. Y por eso las iglesias tienen que limitar su poder. Así se adelanta en el subtítulo del Tratado teológicopolítico: "Contiene varias disertaciones, en las que se demuestra que la libertad de filosofar no sólo se puede conceder sin perjuicio para la piedad y para la paz del estado, sino que no se la puede abolir sin suprimir con ello la paz del estado e incluso la piedad".

\title{
3. Eclipse de toda autoridad, y desaparición de la figura del sabio- moralista, en la Ética
}

Emilia Giancotti, que ha repertoriado la frecuencia del término auctoritas ${ }^{46}$ (o authoritas) en los capítulos fundamentales del Tratado teológico-político y del Tratado político, no incluye ninguna ocurrencia de ese término en la Ética. Sin embargo, la lista presentada por M.Gueret, A.Robinet, P. Tombeur en su tabla de frecuencias detecta una ocurrencia de auctoritas en el Apéndice de la primera parte. El pasaje excepcional dice:

Y de aquí proviene que quien investiga las verdaderas causas de los milagros procura, tocante a las cosas naturales, entenderlas como sabio y no admirarlas como necio, sea considerado hereje e impío, y proclamado tal por aquellos a quienes el vulgo adora como intérpretes de la naturaleza y de los dioses. Porque ellos $^{47}$ saben que, suprimida la ignorancia se suprime la estúpida admiración,

${ }^{45}$ TTP, p. 407 [G III, XVIII, 238].

${ }^{46}$ Giancotti, Emilia: Lexicon Spinozanum, vol 1, 1970, p. 95.

${ }^{47}$ Spinoza se refiere aquí a quienes el vulgo idolatra y sigue, es decir, a los teólogos y metafísicos. 
esto es, se les quita el único medio que tienen de argumentar y de preservar su autoridad $^{48}$.

Las palabras de Spinoza, relacionando la ignorancia del pueblo, su capacidad para la maravilla y la superstición, con la autoridad de los teólogos se inscriben en un conocidísimo pasaje donde se identifica, y se critica, el finalismo y la manipulación de teólogos y metafísicos, que se parapetan tras la figura de un Dios personal trascendente, representado como un ser sabio y todopoderoso, creador y rector del universo.

Esta es la única ocurrencia del término auctoritas en la Ética, ya que la noción no vuelve a aparecer. Hay pues que interrogarse por la razón de esta ausencia. Y, como punto de arranque, proponemos a modo de hipótesis plausible dos posibilidades de interpretación: 1) o el término auctoritas se ha sustituido en el sistema por algún sinónimo o expresión equivalente que conserva el mismo significado de la noción tradicional; 2) o el modelo metafísico basado en el paradigma de la autoridad tradicional ha desaparecido siendo sustituido por otro. En ese caso, la nueva propuesta filosófica deberá incluir otros cambios léxicos y conceptuales. En mi opinión, la alternativa contemplada en la primera opción podría concordar con el trabajo sobre la noción de autoridad realizado por Spinoza en el Tratado teológico-político, a partir de los usos del término; pero este no es el caso en la Ética.

Al contrario, el sistema filosófico de Spinoza habría desmontado todas las tesis metafísicas edificadas sobre la analogía del principio de autoridad, antes de reemplazarlas por el uso adecuado del entendimiento como criterio de autoridad en la conquista por la libertad (reduciendo las coacciones). Cada tesis metafísica demolida se acompaña de una propuesta alternativa, y las consecuencias se encadenan: si la autoridad de un Dios personal y trascendente como rector del universo es rechazada en la primera parte de la Ética (en nombre del Deus sive natura sive substantia), le sigue en la segunda parte la negación del modelo antropológico dualista y hegemónico (porque el orden y conexión de las ideas es el mismo que el orden y conexión de las cosas); y si, en la tercera parte, el control voluntario de las pasiones es refutado en nombre de la universalidad del deseo/conatus, entonces es inútil apoyarse en la autoridad de un sabio en materia de moral (cuarta parte). Por lo que, siendo la mayor potencia y virtud del hombre el uso de su razón, en la quinta parte de la Ética, se propugna una idea de libertad asociada al incremento del conatus propio. Este es el único tipo de poder de la razón frente a los afectos: un poder limitado.

Nuestra propuesta de interpretación defiende que el trabajo crítico realizado por Spinoza en su filosofía pasa por rechazar el principio de autoridad que

48 Etica demostrada según el orden geométrico, Traducción Vidal Peña, Barcelona, Editora Nacional-Orbis, 1980, p. 94 [G II, I Ap, 81]. Subrayado nuestro. 
presidía analógicamente todos los niveles de ser. En la metafísica tradicional la autoridad, como dependencia jerárquica y sometimiento a la voluntad de otro, era un modelo explicativo para todos los órdenes de realidad: el mundo humano refleja el orden cósmico que refleja a su vez el orden divino ${ }^{49}$. Examinemos esta idea con algún detalle.

Ética I analiza y desmonta la ilusión de libertad encerrada en una serie de prejuicios que nacen de una falsa idea de Dios como ser personal y trascendente, sabio y omnipotente. "La superstición -explica Laurent Bove ${ }^{50}$ es el prejuicio más el temor que se manifiesta en cuanto experimentamos una naturaleza caótica, hostil y contraria a nuestros fines. Buscamos entonces desesperadamente un remedio y rendimos culto a los rectores naturae". Spinoza propone "una idea sana de Dios" con su fórmula: Deus sive Natura. A partir de ahí, también Ética II hace saltar el modelo antropológico tradicional basado en la autoridad del alma sobre el cuerpo. Spinoza revoca el dualismo que hace del hombre un alma superior dentro de un cuerpo que debe someterse a ella. Rechaza esa relación de dependencia y propone una interpretación original basada en la igualdad de atributos de la única sustancia (el denominado "paralelismo" antropológico de E2 7esc.). Un corolario se sigue de aquí: ni el cuerpo puede determinar al alma a pensar ni el alma puede determinar al cuerpo al movimiento ni al reposo (E3 2) ${ }^{51}$.

Si pues un lector de Spinoza, decepcionado ante el mutis protagonizado por esas dos concepciones metafísicas de corte autoritario, esperase recuperar la noción de autoridad bajo la figura de la voluntad - como una facultad supuestamente capaz de controlar la esfera pasional, tal como lo pensara Descartes- su expectativa quedaría frustrada. En efecto, la tercera parte de la Ética demuestra geométricamente que el único amo del que cada individuo depende necesariamente es su deseo (conatus individual), un conjunto de fuerzas naturales que -como parte de la potencia infinita de la naturalezaimpulsan a los hombres a ser, existir y actuar. En vano, pues, hallaremos aquel modelo de acción voluntaria según el cual el alma obra libremente en los seres superiores.

Habiendo sido revocada la aplicación analógica de la autoridad en el plano de los afectos humanos, podría parecer que el hombre haya de resignarse a la servidumbre renunciando a la libertad ${ }^{52}$. Mas, con el fin de disolver este temor,

${ }^{49}$ En este sentido valoramos extraordinariamente la tesis de G. Deleuze, quien destaca la univocidad de la causa como fundamento de la inmanencia y la expresión de los atributos como fundamentos de la riqueza metafísica de Spinoza. Cfr. Spinoza y el problema de la expresión, Barcelona, Muchnik, 1975.

${ }^{50}$ La estrategia del conatus. Afirmación y resistencia en Spinoza. Madrid, Tierradenadie ediciones, 2009, p. 185.

51 G II, 141-144.

${ }^{52}$ El término autoridad no figura expresamente en estas partes de la Ética, pero tampoco hace falta, siendo sustituido por los términos servidumbre (E IV, G II, 205) y libertad (EV, G II, 277) que desde la Política de Aristóteles están asociados a la autoridad doméstica. 
Spinoza escribe la cuarta y quinta partes de la Ética: "De la servidumbre humana o de la fuerza de los afectos", donde desarrolla una teoría de la servidumbre. Así como también, la última parte titulada "Del poder del entendimiento o de la libertad humana", que contiene su doctrina sobre la conquista de la libertad. En ellas hay un planteamiento revolucionario frente a las morales tradicionales edificadas sobre el paradigma autoritario ${ }^{53}$. Puesto que no cabe ya el recurso al esquema jerárquico bajo ninguna modalidad, tampoco se reconoce la autoridad del moralista sobre la conducta de los demás. Pues, por una parte, todos los hombres -incluido el hombre sabio- están siempre y necesariamente sometidos a las pasiones. Y, por otra parte, todos los hombres disponen de un entendimiento -aunque no estén dispuestos a servirse de él ${ }^{54}$.

El giro moral propuesto por Spinoza se anuncia explícitamente en el axioma único de la cuarta parte de la Ética, al proclamar urbi et orbi la relativización de todas las fuerzas de la naturaleza: "En la naturaleza -escribe Spinoza- no se da ninguna cosa singular sin que se dé otra más potente y más fuerte. Dada una cosa cualquiera, se da otra más potente por la que aquella puede ser destruida". El filósofo expresa la ley fundamental de la naturaleza, que regula igualmente las interacciones humanas individuales y colectivas ${ }^{55}$.

La ventaja epistémica del modelo reticular potentia-conatus-potestas ${ }^{56}$ -frente al paradigma tradicional basado en la utilización analógica del esquema de autoridad- es que la nueva doctrina no propone la trascendencia de ninguna estructura metafísica, con lo que desaparece también toda forma de jerarquía metafísica. Nada es superior y/o mejor que nada: ni Dios sobre la naturaleza, ni el alma sobre el cuerpo, ni el intelecto sobre los afectos. Ni un hombre sobre otro. Todo cuanto es y existe obra en virtud de la potencia necesaria de la sustancia: "Cada cual existe por el derecho supremo de la naturaleza" ${ }^{57}$. Entonces, podemos interrogarnos, ¿no goza el sabio spinozista

${ }^{53}$ Cfr. Martínez, F.J.: Autoconstitución y libertad, Barcelona, Anthropos, 2007, p. 104: "Las éticas predominantes de la modernidad... evitan la problemática de dicho sujeto y aceptan acríticamente el modelo de sujeto predominante en la tradición judeocristiana..."

54 Algunos estudiosos entre nosotros (pienso en Eugenio Fernández, Gabriel Albiac, Juan Pedro García del Campo) han sugerido en este punto interpretar las interacciones humanas en Spinoza desde el paradigma reticular. Este modelo constituye una alternativa frente al modelo jerárquico tradicional y ve la red de afectos humanos como un complejo dinamismo inmanente que gobierna las relaciones inter e intra-individuales.

${ }^{55} \mathrm{G}$ II, 210. Esto desencadena consecuencias en el plano moral. Una reinterpretación del bien y el mal: "Entiendo por bueno lo que sabemos con certeza que nos es útil". "Por malo, en cambio, lo que sabemos con certeza que impide que poseamos algún bien". También la sociedad es pensada desde una perspectiva naturalista, como un conjunto de individuos que, con afectados con diferentes grados de intensidad por otras fuerzas, son iguales en cuanto al deseo de conservarse y vivir del mejor modo posible.

56 Sobre la relación de semejanza-diferencia entre las nociones de potentia y potestas se ha escrito mucho. Yo sugiero la breve lección de Charles Ramond en Vocabulaire de Spinoza. Paris, Ellipses, 1999. En EI 35 potestas equivale a potentia (noción que se acaba de definir en la proposición anterior); los empleos en E5 y prefacios apuntan críticamente al modelo antropológico y ético de Descartes.

${ }^{57}$ E 437 esc 2, p. 282 [G II, 237]. Para la interpretación de este complejo escolio, remito al 
de un estatus especial entre los hombres, por ser una especie de tutor moral, una autoridad basada en el imaginario control del alma sobre el cuerpo?

No hallamos en la Ética nada parecido. Spinoza proclama sencillamente que: "el hombre que se guía por la razón es más libre en el estado, donde vive según leyes que obligan a todos, que en la soledad donde sólo se obedece a sí mismo". Y el Prefacio de la quinta parte contiene una crítica tan feroz como lúcida de una idea de libertad edificada sobre el modelo de autoridad tradicional: bien como superioridad de la razón sobre los sentidos (característico del estoicismo), bien de la potestas de la voluntad sobre los apetitos (en clara denuncia del modelo cartesiano).

A la vista de todo lo dicho en este apartado, cabe afirmar que la desaparición de la autoridad en la Ética no es un eclipse fruto del azar. Ante bien, su cese ha sido forzado por Spinoza con ayuda de la razón y la fuerza de la experiencia. El mutis responde justamente a la postura crítica de la Ética respecto a cualquier pauta metafísica trascendente y jerárquica. La Ética es entonces el sistema de la eliminación (junto con una propuesta alternativa) de la autoridad tradicional como modelo metafísico. Su destrucción implicará a fortiori la eliminación de cualquier figura o entidad revestida de grandeza y majestad ${ }^{58}$, así como de los tutores morales -sean personas, facultades o entidades; $\mathrm{y}$, por supuesto, el rechazo de la hegemonía del filósofo por encima de los demás hombres:

La autoridad de Platón, de Aristóteles y de Sócrates no vale mucho para mí. Me hubiera admirado que usted hubiera aducido Epicuro, Demócrito, Lucrecio o alguno de los atomistas y defensores de los átomos...Si usted pretende servirse de la creencia en ellos, ¿qué razones tiene usted para negar los milagros de la Virgen divina y de todos los santos referidos por tantos filósofos, teólogos e historiadores celebérrimos...? (Carta 56 a Hugo Boxel, 1674).

El reconocimiento de la autoridad intelectual tiene su origen, lo mismo que la autoridad eclesial, en la maravilla, en la admiración y en la veneración que sentimos por alguien cuyo criterio seguimos: "Si lo que nos asombra es la prudencia de un hombre, su industria o algo de este género, el asombro se llama veneración, pues pensamos que en virtud de eso que admiramos, ese hombre nos supera en mucho;... si ese asombro va unido a un hombre a quien amamos,

\footnotetext{
lector al trabajo colectivo (Martínez, F. J.; de la Cámara, M. L.; Peña, J.; Roldán, C. y Rodríguez, R.: "Comentario de E4p37S2: Cinco perspectivas", en Blanco, Jesús: Espinosa: Ética e política, Santiago de Compostela, Universidade de Santiago de Compostela, 1999, pp. 487-499.

${ }^{58}$ En Principia philosophia cartesiana- Cogitata metaphysica (1663-1664) Spinoza se deshace de las entidades metafísicas tradicionales y propone nuevos esquemas de explicación de lo real. En este terreno son de gran utilidad las reflexiones de Chantal Jaquet sobre las nociones de la gran tradición metafísica en Spinoza: Sub specie aeternitatis. Étude des concepts de temps, durée et éternité chez Spinoza, París, Kimé, 1997; «Le problème de 1'attribution de l'étendue à Dieu», Les Pensée métaphysiques de Spinoza (Dir), Paris, Pub. de la Sorbonne, 2004.
} 
lo llamamos devoción" (E3 52 esc) $)^{59}$. Enseguida la mente clasifica y etiqueta sus cualidades construyendo determinados clichés o estereotipos intelectuales y morales: "Así pues, en la medida en que reducimos los individuos de la naturaleza a este género y los comparamos entre sí y encontramos que unos tienen más entidad o realidad que otros, en esa medida decimos que unos son más perfectos que otros...", precisará el Prefacio de la cuarta parte.

Sin embargo, en realidad, el paso fehaciente de alguien a una mayor o menor perfección no consiste sino en el aumento o disminución de su potencia de obrar. La presencia masiva de nociones nuevas para explicar las cosas humanas, como conatus, afectos, potencia $^{60}$ (fuerza natural) y potestas acreditará en el plano terminológico la transformación operada sobre el antiguo paradigma de la acción y el perfil naturalista del nuevo modelo. El nuevo marco interpretativo, siendo de aplicación universal, define -desde la perspectiva de una lógica inmanente- las relaciones humanas como un dinamismo de fuerzas necesarias y cambiantes, siempre relacional y situado más allá del bien y del mal. La crítica de Spinoza al moralismo es mucho más que un alegato contra un tirano o contra los tutores (como harán: Kant en ¿Qué es Ilustración?, y Fichte en Reivindicación de la libertad de pensar). Spinoza analiza y deduce genéticamente los mecanismos cognitivos de los prejuicios, los afectos y pasiones que subyacen al menosprecio y a la burla satírica, las manipulaciones de los teólogos, políticos y metafísicos dispuestos a someter a una población que los autoriza y los rechaza: "Quien se esfuerza por el solo afecto en que los demás amen lo que él ama y en que los demás acomoden su vida a la índole de él, se hace odioso" (E4 37 esc2). Se trata efectivamente de algo parecido al caso de los profetas que "dotados de virtud divina, más bien irritaron que corrigieron a los hombres con su libertad de amonestar, de increpar y de recriminar mientras los reyes les doblegaron fácilmente con sus recriminaciones y castigos"61.

La Ética pone punto final a cualquier autoridad metafísica y moral por encima de la propia naturaleza, incluida la autoridad del sabio (E4 45 esc), que es sustituida por el criterio del hombre libre. Y consuma en esta obra el proyecto de revisión crítica de la autoridad iniciado en el Tratado teológico-político, defendiendo que el poder del hombre se determina no tanto por la razón cuanto por el deseo de supervivencia ${ }^{62}$. Conservación y potencia coinciden en Spinoza, tal como subraya Matheron:

59 Pasiones relacionadas con la autoridad: G II, 180, p. 184. Por ello, para Spinoza es muy importante que cada uno se valore adecuadamente sin caer en la auto-humillación ni en la soberbia.

${ }^{60} \mathrm{La}$ frecuencia del término potentia la Ética es de 198 (58 en la IV parte); potestas cuenta con 35 ocurrencias.

${ }^{61}$ TTP XIX, p. 403 [G III, 236].

62 TP II, 5. Cfr. García del Campo, Juan Pedro: Spinoza o la libertad, Ed. Montesinos, 2008, p. 62: "No es un cálculo racional el que mueve a los hombres a cooperar sino el despliegue inmanente de las leyes naturales que les exigen buscar la supervivencia. La racionalidad no es, por tanto, la norma de conducta: es en todo caso una estrategia que aporta a la exigencia natural un mayor grado de eficacia". 
Tout être, à chaque instant, fait nécessairement tout ce qu'il peut, et, aussi longtemps qu'il peut quelque chose, il se conserve. Cet effort, ou conatus, c'est le désir. Désir toujours légitime: puisque notre puissance est la puissance meme de Dieu, nous avons le droit de faire tout ce qu'elle nous determine à faire, ni plus ni moins"

\section{Uso pragmático de la autoridad en las diversas constituciones}

En el capítulo II del Tratado político Spinoza se hace eco de lo dicho en las dos obras anteriores y redacta las líneas maestras de su teoría sobre el poder: el derecho de la potestad suprema -acorde con el dictado de la razón y con los imperativos de supervivencia- será mayor cuanto mayor sea su poder, y tanto más eficaz será también en la consecución de la paz y la libertad. A diferencia del fuerte enfoque crítico y del tratamiento genealógico dado a la autoridad en las obras comentadas en los apartados anteriores, en el Tratado político Spinoza reconduce la cuestión llevándola al plano cívico-político, centrado en el reparto de poderes del estado y su distribución equilibrada con vistas a ordenar los asuntos comunes. "L'État, -señala lúcidamente A. Matheron, apuntando a la producción de nuevos poderes- on le voit, n'abolit nullement les micro-pouvoirs de l'interaction desquels il résulte, et hors de l'interaction desquels il n'est rien. Mais il les stabilise, les spécialise, les redistribue selon des structures globales ajustées les unes aux autres; et il en crée aussi de nouveaux, qui s'organisent à leur tour de façon à assurer cette redistribution elle-même" ${ }^{\prime 4}$.

El propósito de Spinoza en su última obra será mostrar cómo ha de organizarse ese reparto de funciones políticas para que el estado (summa potestas) no degenere en tiranía ${ }^{65}$. El filósofo podría haber tenido presente al escribir su tratado la denuncia de la tiranía realizada por Étienne de la Boétie en su Discurso sobre la servidumbre voluntaria. El amigo de Montaigne reflexiona en esas páginas sobre el fenómeno habitual de la sumisión del pueblo a un tirano, una auténtica voluntad de sujeción, atribuible no a la naturaleza (que no ha hecho esclavos a los hombres, sino iguales y hermanos), sino a la costumbre y la educación, a las distracciones públicas como entretenimientos y juegos, al reparto de favores y prebendas, a la aceptación pasiva del poder, al abuso de la religión, todo lo cual fomenta la renuncia a la libertad.

\footnotetext{
${ }^{63}$ Matheron, A.: "Spinoza et le pouvoir", op. cit, p. 69.

${ }^{64}$ Matheron, A.: "Spinoza et le pouvoir", op. cit., p. 77. Estos poderes son económicos, gubernamentales, ideológicos y militares.

${ }^{65}$ Marilena Chaui escribe: "En verdad, sin embargo, Spinoza propone un remedio contra la causa de la tiranía: El Tratado político. (...) Por ese motivo cada uno de los capítulos dedicados a las diferentes formas políticas presenta para cada una de ellas un conjunto de instituciones públicas capaces de garantizar que costumbres, leyes y prácticas sociopolíticas funden o conserven una forma política según las exigencias del derecho natural, de los tiempos y de los lugares...", "La institución del campo político", Política en Spinoza, Buenos Aires, Gorla, 2004, p. 203.
} 
Spinoza, próximo a las preocupaciones del humanista, se propone -según confirma el subtítulo del Tratado político: En el que se demuestra cómo se debe organizar una sociedad en la que existe un estado monárquico, así como aquella en la que gobiernan los mejores, a fin de que no decline en tiranía y se mantengan incólumes la paz y la libertad de los ciudadanos ${ }^{66}$ - determinar el peso que tienen que tener las cámaras, consejos y camarillas políticas para que no desequilibren el poder político, manteniendo un reparto compensado de funciones para cada una de las principales figuras constitucionales: monarquía, aristocracia, democracia.

Marilena Chaui ha conectado expresamente las propuestas de constitución de Spinoza en el Tratado político con la situación concreta de Holanda. La autoridad gubernamental tenía desde mediados del siglo XVI dos fuentes: el contrato del príncipe con el pueblo y el poder de las asambleas provinciales y corporaciones urbanas (es decir, los estados): "Es la delicada balanza del poder, concepto tan caro a los políticos holandeses del siglo XVII, lo que debe mantenerse en equilibrio perfecto. El desequilibrio proviene de que el príncipe se ponga contra los estados o de que el pueblo sea persuadido a ponerse contra ellos, de suerte que efectivamente los estados son la balanza del poder" ${ }^{\text {"67. Sin }}$ embargo, subraya, esto es lo que Spinoza modifica: "el Tratado político tiene el mismo efecto que, antes que él, había tenido el Tratado teológico-político: brilla como un rayo en el cielo azul" ${ }^{68}$. Por una parte, el filósofo no reconoce al pueblo otro derecho a derribar al tirano que el que depende de su fuerza, es decir, de la propia potencia de la multitudo para hacerlo ${ }^{69}$; y, por otra parte, no existe contrato alguno entre el pueblo y el príncipe. En consecuencia, la estabilidad del estado y su conservación dependen del correcto ordenamiento constitucional -dada la naturaleza pasional de todos los hombres, gobernantes y gobernados. Spinoza, desde una perspectiva "política de la desutopía"70 abre una brecha en el tiempo histórico proyectándose hacia un futuro protagonizado por diferentes proyectos de liberación.

Sin ánimo de entrar en pormenores, queremos recoger sumariamente algunas de las consideraciones políticas más relevantes de Spinoza en relación con la cuestión que nos ocupa. En la constitución monárquica (capítulos VI y VII) la armonía no es difícil de conseguir (al menos, sobre el papel): “Concluimos

${ }^{66}$ Tratado político, Trad.,Intr., Índice y Notas de A. Domínguez, Madrid, Alianza, 1986, p. 74 [G III, 273].

67 “Quién le tiene miedo al pueblo?”, en Politica en Spinoza, op. cit., p. 284.

${ }^{68}$ Chaui, M.: op. cit. p. 288.

69 Sobre este punto resultan recomendables las lecturas de los libros: Caporali, Ricardo; Morfino, Vittorio y Visentin, Stefano (Dir): Spinoza: Individuo e moltitudine, Bologna, Ponte Vecchio, 2007; así como el de Filippo Del Lucchese, Tumultes et indignation. Préface, A. Negri, Paris, Éditions Amsterdam, 2010

${ }^{70}$ Cfr. Negri, A.: La anomalia salvaje, Ensayo sobre poder y potencia en Spinoza, Barcelona, Anthropos, 1993, p. 357.

Araucaria. Revista Iberoamericana de Filosofía, Política y Humanidades, año 20, n 39. Primer semestre de 2018. Pp. 227-250. ISSN 1575-6823 e-ISSN 2340-2199 doi: 10.12795/araucaria.2018.i39.11 
que la multitud puede mantener bajo el rey una libertad suficientemente amplia, con tal que logre que el poder del rey se determine por el solo poder de esa misma multitud y se mantenga con su solo apoyo. Esta es la única regla que yo he seguido al establecer las bases del estado monárquico" - escribe el filósofo al final del capítulo VII. Habrá, por tanto, que prestar mucha atención al Consejo (autoridad) para escuchar sus opiniones sin que nadie se apodere de la voluntad del monarca (máximo poder) cuyo fin es servir al pueblo.

En cuanto a la constitución aristocrática del estado (que distingue entre patricios y plebe), deberá conservar de manera prioritaria la potestad suprema del estado jerarquizando la autoridad de los diversos consejos al poder del Consejo Supremo. En efecto, como los derechos del estado están encarnados en el Consejo Supremo hay que "procurar en primer término que se apoyen en la voluntad y el poder de su Consejo Supremo de suerte que éste sea, en la medida de lo posible, autónomo y la multitud no signifique para él amenaza" (TP $§ 7$, p. 170 [G III, 326]). Su función será legislativa y podrá elegir a los cargos públicos. A éste queda subordinado cualquier otro Consejo. El Consejo de Síndicos; así como el Senado (§29, p. 183), por ejemplo, están subordinados a aquel ${ }^{71}$.

Así expresaba Cicerón (De legibus) la necesidad de equilibrio entre autoridad y poder: "Cum potestas in populo auctoritas in senatu sit". Spinoza refrendará la fórmula ciceroniana en estos términos:

\begin{abstract}
Al establecer las bases del estado aristocrático hemos observado ante todo estas dos condiciones, a saber, que la plebe quedara apartada de las deliberaciones como de las votaciones (...) Por eso hemos establecido que la suprema potestad del estado resida en todos los patricios, la autoridad en cambio en los síndicos y en el Senado, y finalmente el derecho de convocar el Senado y (de proponerle) los asuntos relativos al bien común, en los cónsules elegidos del mismo Senado $^{72}$.
\end{abstract}

Matheron enumera atinadamente las claves de las soluciones propuestas por Spinoza: máxima democracia compatible con la naturaleza del régimen en cuestión, supresión de todo feudalismo, y máximo desarrollo del comercio y de la tolerancia religiosa. “(...) l'État, même le meilleur, n'est la réalisation ni de la raison ni de la liberté; rien que des rapports de forces sur la base d'une aliénation généralisée"

71 "Nunca faltarán en el Senado varones eminentes que destaquen por su prudencia y habilidad" (p. 185). Por eso su preocupación es buscar la manera de que conserven su libertad y tengan "igual autoridad en sus decisiones" (TP, p. 182).

72 TP, p. 196 [G III, 344].

${ }^{73}$ Matheron, A.: op. cit. p. 79. 


\section{Reflexión penúltima sobre la autoridad}

Hemos llegado al final del presente trabajo que se proponía recuperar las líneas maestras de la reflexión de Spinoza sobre la autoridad. Lamentablemente hemos tenido que pasar por alto algunos matices, hemos omitido referencias y no hemos resuelto todas las dificultades. Bien mirado, es mejor así: una empresa de este tipo debe quedar siempre abierta a nuevas sugerencias y confrontada con otras propuestas de interpretación.

Pero una cosa es clara: la autoridad es un motivo principal en la filosofía de Spinoza, que ha trabajado la noción de diferentes formas en cada una de sus obras de madurez. El libro de 1670 examina las causas del conflicto entre la autoridad eclesial y el poder del estado, y, lejos de suprimir la autoridad, Spinoza esclarece sus usos y delimita sus competencias en un estado tolerante. Se rechaza la validez universal de la teocracia hebrea y la autoridad del Romano Pontífice, en nombre de la libertad de expresión. La Ética da un paso más en la crítica al desmontar el modelo de autoridad utilizado analógicamente por la industria metafísica tradicional. Los tutores intelectuales y morales, incluidas las entidades metafísicas tradicionales, desaparecen también. La tarea crítica de Spinoza ha terminado. Es en este punto de su itinerario, en el Tratado político, donde el filósofo recupera la noción para, una vez clarificada a la luz de su filosofía, ponerla pragmáticamente al servicio de la política. La cuestión entonces será diseñar aquellos modelos institucionales donde se equilibren las autoridades y el poder de la multitud para impedir la tiranía.

Pedro Calderón de la Barca en su auto sacramental "El gran teatro del mundo" hacía un relato alegórico de los mecanismos ocultos que gobiernan la fábrica del universo. Nada más finalizar el Rey su discurso -donde enumera con orgullo todos sus poderes y sus atributos-, el Mundo le responde: "Pues deja, suelta, quita la corona;/ la majestad, desnuda, pierde, olvida;/ vuélvase, torne, salga tu persona, / desnuda de la farsa de la vida/. La púrpura, de quien tu voz blasona, /presto de otro será vestida, / porque no has de sacar de mis crueles/ manos, púrpuras, cetros ni laureles" $" 74$.

No tenemos constancia de que Spinoza haya leído este pasaje. Pero tampoco sabemos a ciencia cierta que no lo haya hecho. Calderón y Spinoza reaccionan -aquel desde la imaginación y con recursos literarios, éste desde la razón y la historia- al mucho sufrimiento generado en los hombres por esa forma de interacción de corte autoritario, pieza clave en la industria social. Sin embargo, pese a sus denuncias, las interacciones basadas en la autoridad continúan vigentes en nuestros días, y los tutores, aunque parecían haber sido evacuados, reaparecen con fuerza renovada multiplicándose por doquier. La lectura de Spinoza es hoy más necesaria que nunca.

\footnotetext{
${ }^{74}$ Calderón de la Barca, Pedro: Autos sacramentales I, Zaragoza, Ebro, 1940, p. 68.
} 


\section{Referencias bibliográficas:}

San Agustín: La Ciudad de Dios, Obras completas, Edición Bilingüe, vol. XVI y XVII, Madrid, BAC, 2004.

Arendt, Hanna: “¿Qué es autoridad?”, Entre el pasado y el futuro, Barcelona, Península, 1996.

Aristóteles: Política. Traducción, introducción y notas de Manuela García Valdés. Madrid, Gredos, 1988.

Calderón de la Barca, Pedro: Autos sacramentales I, Zaragoza, Ebro, 1940.

de la Cámara, María Luísa: "Defensa de la razón por Spinoza", en Ribeiro-

Ferreira, M. Luisa et al. (eds.): Spinoza. Ser e agir. Lisboa, CFUL, 2011.

Caporali, Ricardo; Morfino, Vittorio y Visentin, Stefano (Dir): Spinoza:

Individuo e moltitudine, Bologna, Ponte Vecchio, 2007.

Chaui, Marilena: Politica en Spinoza, Buenos Aires, Gorla, 2004.

Deleuze, Gilles: Spinoza y el problema de la expresión, Barcelona, Muchnik, 1975.

Espinosa, Francisco Javier: "Religión, salvación y autonomía en Spinoza”, en

Blanco, J. (coord.), Espinosa. Ética e política. Santiago de Compostela,

Universidade de Santiago de Compostela, 1999.

_

Schleiermacher, Bonhoeffer y Cox", Cuadernos Spinoza n 7, Ciudad

Real, 1996.

García del Campo, Juan Pedro: Spinoza o la libertad, Ed. Montesinos, 2008.

- La estrategia del conatus. Afirmación y resistencia en Spinoza. Madrid,

Tierradenadie ediciones, 2009.

Giancotti, Emilia: Lexicon Spinozanum, 2 vols, La Haya, M. Nijhoff, 1970.

Guénon, René: Autoridad espiritual y poder temporal, Barcelona, Paidós, 2001. Hermosa, Antonio: La Teoría del estado de Spinoza, Sevilla, Servicio de Publicaciones de la Universidad de Sevilla, 1989.

Hobbes, Tomas: Leviatán: La materia, forma y poder de un estado eclesiástico

y civil. Introducción, Prólogo y Notas de C. Mellizo, Madrid, Alianza, 2009.

Jaquet, Chantal: Sub specie aeternitatis. Etude des concepts de temps, durée et éternité chez Spinoza, París, Kimé, 1997.

(Dir), Les Pensées métaphysiques de Spinoza, Paris, Publications de la Sorbonne, 2004.

Jiménez, Florencio: "Perspectivas teóricas y definicionales sobre poder y autoridad", F. Jiménez (Coord), Psicología de las relaciones de autoridad y poder, Barcelona, UOC, 2006.

Locke, John: Ensayo y Carta sobre la tolerancia. Introd, C. Mellizo, Madrid, Alianza, 1999. 
Del Lucchese, Filippo: Tumultes et indignation. Conflit, droit et multitude chez Machiavel et Spinoza, Préface, A. Negri, Paris, Éditions Amsterdam, 2010. Martínez, F. J.: Autoconstitución y libertad, Barcelona, Anthropos, 2007.

Martínez, F. J.; de la Cámara, M. L.; Peña, J.; Roldán, C. y Rodríguez, R.: "Comentario de E4p37S2: Cinco perspectivas", en Blanco, J.: Espinosa: Ética e política, Santiago de Compostela, Universidade de Santiago de Compostela.

Matheron, Alexandre: Le Christ et le salut des ignorants, Paris, Aubier, 1971

—_ A. Matheron, Études sur Spinoza et les philosophies de l'âge classique, Lyon, ENS, 2011.

Moreau, Pierre-François: "Spinoza et l'autorité d'un modèle: l'État des Hebreux", Spinoza. État et religion, Lyon, ENS Éditions, 2005.

—, Spinoza. L'expérience et l'éternité, Paris, PUF, 1994.

Negri, Antonio: La anomalía salvaje, Ensayo sobre poder y potencia en Spinoza, Barcelona, Anthropos, 1993.

Paricio, J y Fernández, A.: Historia del derecho romano y su recepción europea, Madrid, Centro de Estudios Ramón Areces, 1997.

Ramond, Charles en Vocabulaire de Spinoza. Paris, Ellipses, 1999.

Spinoza: Spinoza Opera. Carl Gebhardt, 4 vols. Heidelberg, C. Winter, 1972 [1 $1^{\text {a }}$ ed. 1925].

Spinoza: Etica demostrada según el orden geométrico, Traducción Vidal Peña, Barcelona, Editora Nacional-Orbis, 1980.

Spinoza: Correspondencia. Traducción, introd. y notas, A. Domínguez, Madrid, Alianza, 1988.

Spinoza: Tratado teológico-político, Traducción, introducción y notas A. Domínguez, Madrid, Alianza, 1986.

Spinoza: Tratado político, Trad.,Intr., Índice y Notas de A. Domínguez, Madrid, Alianza, 1986.

Vallespín, Fernando: "El poder político y los orígenes del estado", Psicología de las relaciones de autoridad y de poder. Jiménez, F. (Coord.), Barcelona, UOC, 2006.

VVAA, Groupe de recherches Spinozistes no 4, L'Écriture Sainte au temps de Spinoza et dans le système spinoziste. Paris, Presses Universitaires de Paris-Sorbonne, 1992. 